\title{
Effect of Different Prehydrolysis Processes on Lignin Extractability of Coconut Husk Fibres
}

\author{
Bryan Carre, ${ }^{1}$ Marc Hebrant, ${ }^{1}$ Nicolas Brosse,${ }^{1 *}$ Nur Hanis Abd. Latif, ${ }^{2}$ \\ and Mohd Hazwan Hussin ${ }^{2 * *}$ \\ ${ }^{1}$ Faculte des Sciences et Techniques, Universite de Lorraine, \\ Bld des Aiguillettes, F-54500, Vandoeuvre-les-Nancy, France \\ ${ }^{2}$ Materials Technology Research Group (MaTReC), School of Chemical Sciences, \\ Universiti Sains Malaysia, 11800 USM Pulau Pinang, Malaysia \\ *Corresponding authors: Nicolas.Brosse@univ-lorraine.fr*; mhh@usm.my**
}

Published online: 25 December 2019

To cite this article: Carre, B. et al. (2019). Effect of different prehydrolysis processes on lignin extractability of coconut husk fibres. J. Phys. Sci., 30(Supp. 2), 207-219, https://doi.org/10.21315/jps2019.30.s2.18

To link to this article: https://doi.org/10.21315/jps2019.30.s2.18

\begin{abstract}
Lignin is a biopolymer usable in many ways once it has been separated and delignified from biomass. In this training report, delignification of coconut husk fibres is performed, with the aim of recovering isolated lignin. In order to do so, different processes are carried out (autohydrolysis, dilute acid, organosolv and soda pulping treatments). The obtained lignin is characterised afterwards through Fourier transform infrared (FTIR), $1 H$ and $13 C$ nuclear magnetic resonance (NMR) in order to check lignin presence and quality. Analyses show that lignin is indeed obtained in both experiments, though the yield is greater for the treatment with autohydrolysis. However, the global yield is quite low, adjustments of experimental parameters (time, temperature, ratio) shall be carried out.
\end{abstract}

Keywords: Biomass, delignification, coconut husk, organosolv, autohydrolysis

\section{INTRODUCTION}

Coconut husk, a common and substantial part of biomass, is one of the main industrial and agricultural wastes in South Asia. Coconut husk fibres are a natural product that can be used to produce useful matter or energy. 
The cell walls of coconut husks fibres are made of three biopolymers: lignin, cellulose and hemicellulose, and are naturally present on earth. They can be used to convert biomass into renewable energy or useful chemicals, which is part of a big challenge humanity has to overcome since fossil energies has become rarer.

The three biopolymers exhibit different properties. Cellulose is a crystalline polymer made up of only glucose. It hardly undergoes hydrolysis. Hemicelluloses, on the other hand, are amorphous polymers made of several saccharides (xylose, mannose, glucose, etc.) that can undergo hydrolysis. As it is made of different sugars, there is not one but several hemicellulose structures. Lignin is an amorphous polymer with an intricate structure made of three different motifs, bound to each other by specific linkages. Like hemicelluloses, a unique structure does not exist. Each of these motifs are labelled H, G and $\mathrm{S}$ as shown in Figure 1. As for biomass, cell walls of plant material are a mix of cellulose, hemicellulose and lignin. Lignin is the binder of cellulose and hemicellulose, as shown in Figure 2.

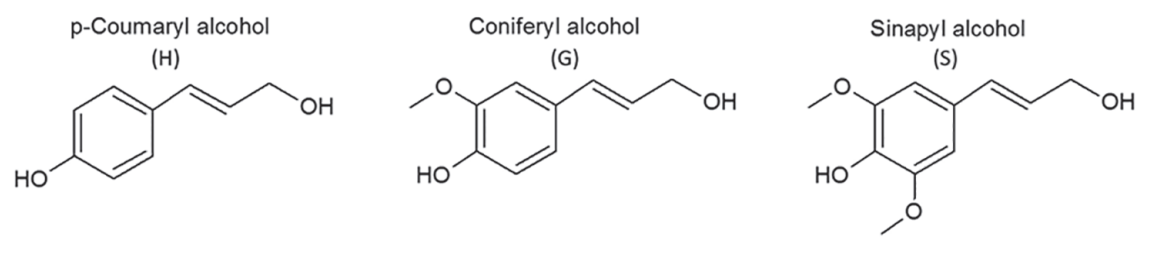

Figure 1: Lignin sub-units.

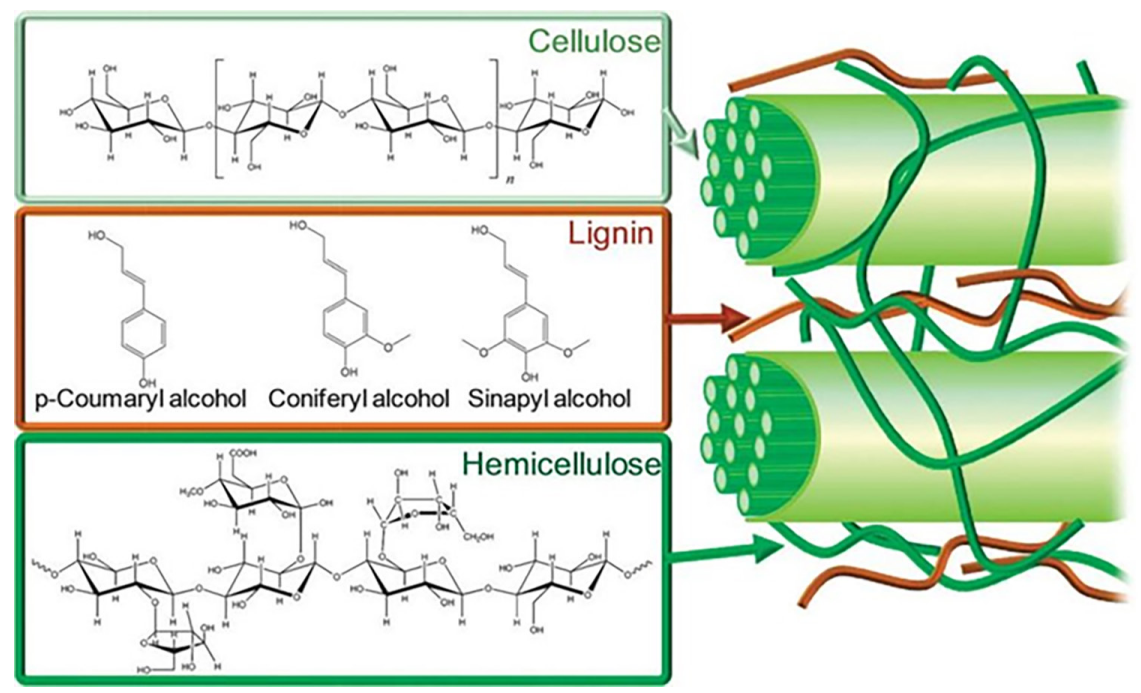

Figure 2: Biomass structure. ${ }^{1}$ 
However, in the treatment of biomass, it is more convenient to use these three biomolecules when they are isolated as higher yield can be achieved if these three biomolecules are used separately. Therefore, several processes allowing separation of these three components have been found and studied. ${ }^{2}$

In this context, four different types of delignification processes will be performed to separate lignin from hemicellulose and cellulose. Eventually, obtained lignin will be characterised through nuclear magnetic resonance (NMR) $\left({ }^{1} \mathrm{H}\right.$ and $\left.{ }^{13} \mathrm{C}\right)$ and Fourier transform infrared (FTIR) spectroscopy.

The global objective of this work as well as the numerous related studies, is to separate intricate natural polymer molecules, present is huge quantity on earth, in a renewable way, in order to turn them into useful products or energy, in the scope of developing sustainable chemistry. Coconut husk fibres is chosen for this work as it is known to be non-toxic, relatively easy to use chemically, rich in lignin, and stronger than other natural fibres found in biomass.

\section{EXPERIMENTAL}

\subsection{Proximate Analysis}

Coconut husks have been firstly characterised through simple proximate analysis. This analysis is useful to investigate the contents in coconut husks, such as biomass molecules content or ash and moisture contents.

In order to carry out these experiments, the traditional variety coconut husks (Malaysian Tall species) were collected in the state of Kedah, Malaysia. Coconut husks had to be ground using a blender (Waring commercial blender) and sifted with a $0.25 \mathrm{~mm}$ sieve. A powder was obtained and used in the experiments of this work. Each experiment is triplicated, and the average results are displayed.

\subsection{Pre-treatment Processes}

Common processes of delignification are sulfie, Kraft, soda and aqueous ethanol organosolv processes, steam explosion and enzyme. ${ }^{3}$ If lignin obtained through sulfite process can be used as dispersant, emulsifier, or ion-exchange resin and Kraft lignin as lignin for biofuel production, it would be interesting to develop organosolv process. ${ }^{4-6}$ 
However, considering a major drawback can happen on organosolv-treated (and soda-treated) lignins, namely degradation of hemicelluloses into undesired products such as furfural or hydroxymethylfurfural (HMF), a two-step pre-treatment process is usually considered to be a good option. In order to do so, autohydrolysis (also called water treatment), or dilute acid treatment, will be performed prior to organosolv and soda pulping processes.

\subsubsection{Autohydrolysis}

Autohydrolysis is known to be the most environment-friendly process as it uses only water. The principle is based on the cleavage of glycisodic bonds in hemicelluloses (ether linkage between two molecules of glucose). Furthermore, the splitting will generate hemicellulose by-products able to dissolve in the hydrolysis solution since the degree of polymerisation has been reduced. On the other hand, lignin will undergo some fragmentation but will remain insoluble in the hydrolysis solution.

The autohydrolysis occurs in a $500 \mathrm{ml}$ reactor at pressure value 10-12 bars where a ratio of $1: 15$ (solid:liquid) is heated at $150^{\circ} \mathrm{C}$ for about $6 \mathrm{~h}$ at $600 \mathrm{rpm}$. Solid corresponds to blended and sieved coconut husks powder. Liquid is plain distilled water. The reactor used is a KeXing Instruments TGYF, a miniature desktop highpressure reactor. The same reactor is used for each experiment.

\subsubsection{Dilute acid treatment}

Dilute acid treatment is another way of hydrolysing hemicellulose by breaking polymeric bonds. Usually, inorganic acids, $\mathrm{H}_{2} \mathrm{SO}_{4}$ or $\mathrm{HCl}$, are used in low concentration. Indeed, high concentrations of acids are known to produce undesirable HMF and generate corrosion problems.

A solid:liquid ratio of $1: 20$ is stirred for $24 \mathrm{~h}$ using sulfuric acid as the solvent $\left(0.9 \% \mathrm{H}_{2} \mathrm{SO}_{4} \mathrm{wt}\right.$.). The mixture is then heated to $170^{\circ} \mathrm{C}$ for $2 \mathrm{~min}$. The obtained pulp is filtrated, and oven dried at $50^{\circ} \mathrm{C}$.

After the pre-treatment operation, a phase mixture will be obtained. The liquid (the filtrate) does contain sugars that could be analysed, but these analyses will not be part of this work. The precipitate, will be recovered, washed with warm water $\left(80^{\circ} \mathrm{C}\right.$, around $\left.800 \mathrm{ml}\right)$ and dried at $50^{\circ} \mathrm{C}$. In order to see if lignin has been hydrolysed during the process, a Klason lignin experiment (such as done in proximate analysis) will be performed. The remaining pulp will represent the solid part in organosolv and Soda pulping processes. 


\subsection{Delignification Processes}

\subsubsection{Organosolv pre-treatment}

Organosolv process entails the use of an aqueous alcohol solution that degrades lignin under high temperature. Classic solvents such as methanol, ethanol, butanol, ethylene glycol or acetic acid can be used in this process. Ethanol is the most convenient, because it removes lignin from the precipitate by making it soluble in the solvent and it can be recycled using flash distillation.

Therefore, in this experiment, solvent is ethanol (used in an aqueous mixture of $65 \% \mathrm{EtOH}, 35 \% \mathrm{H}_{2} \mathrm{O} \mathrm{v} / \mathrm{v}$ ). Solid:liquid ratio is $1: 10$, the mixture is put in the reactor, heated at $190^{\circ} \mathrm{C}$ for $1 \mathrm{~h}$ and stirred at $800 \mathrm{rpm}$. The liquid part (liquor) is recovered, while the solid part, where hemicellulose and lignin contents have been lowered will not be used in this work but can undergo other pre-treatment with the aim of biofuel production.

The liquor is then filtrated and washed with $150 \mathrm{ml}$ of aqueous ethanol $(80 \%$

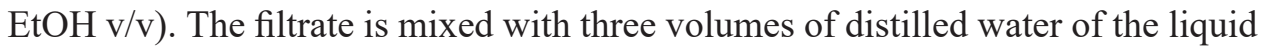
volume obtained, so as to form a precipitate, and the mixture is then stored in a fridge for 3 days. The mixture precipitate is eventually recover through centrifuged (3500 rpm, $10 \mathrm{~min}$ ) and dried at $50^{\circ} \mathrm{C}$ for overnight.

\subsubsection{Soda pre-treatment}

Soda pre-treatment is another way to extract lignin. It uses an alkaline solution of $30 \%(\mathrm{w} / \mathrm{v}) \mathrm{NaOH}$. Sodium hydroxide pellets are used and dissolved in distilled water. Solid to liquid ratio is $1: 15$, temperature is $170^{\circ} \mathrm{C}$, and time is $3 \mathrm{~h}$. The mixture is put in the same $500 \mathrm{ml}$ reactor as before at pressure 10-12 bars.

After pre-treatment, black liquor obtained is filtrated and the liquid part is recovered. It is acidified with $\mathrm{H}_{2} \mathrm{SO}_{4}(20 \%$ wt) until $\mathrm{pH} 2$ is reached. A precipitate is formed.

The formed precipitate is recovered through centrifugation same as organosolv treatment. The solid is then washed with $150 \mathrm{ml}$ acidic distilled water $(\mathrm{pH}=2$ acidified with $\mathrm{H}_{2} \mathrm{SO}_{4} 20 \%$ ), gravity filtered and eventually oven dried at $50^{\circ} \mathrm{C}$ for overnight. 


\subsubsection{Lignin recovery}

The lignin from organosolv and Soda processes will then calculated using this formula in order to obtained percentage yield of lignin recovery:

$$
\text { Yield } \%=\frac{\text { Mass of lignin recovered }(\mathrm{g})}{\text { Mass of coconut husk power }(\mathrm{g})} \times 100
$$

An overview of every methods done in this work is given in Figure 3.

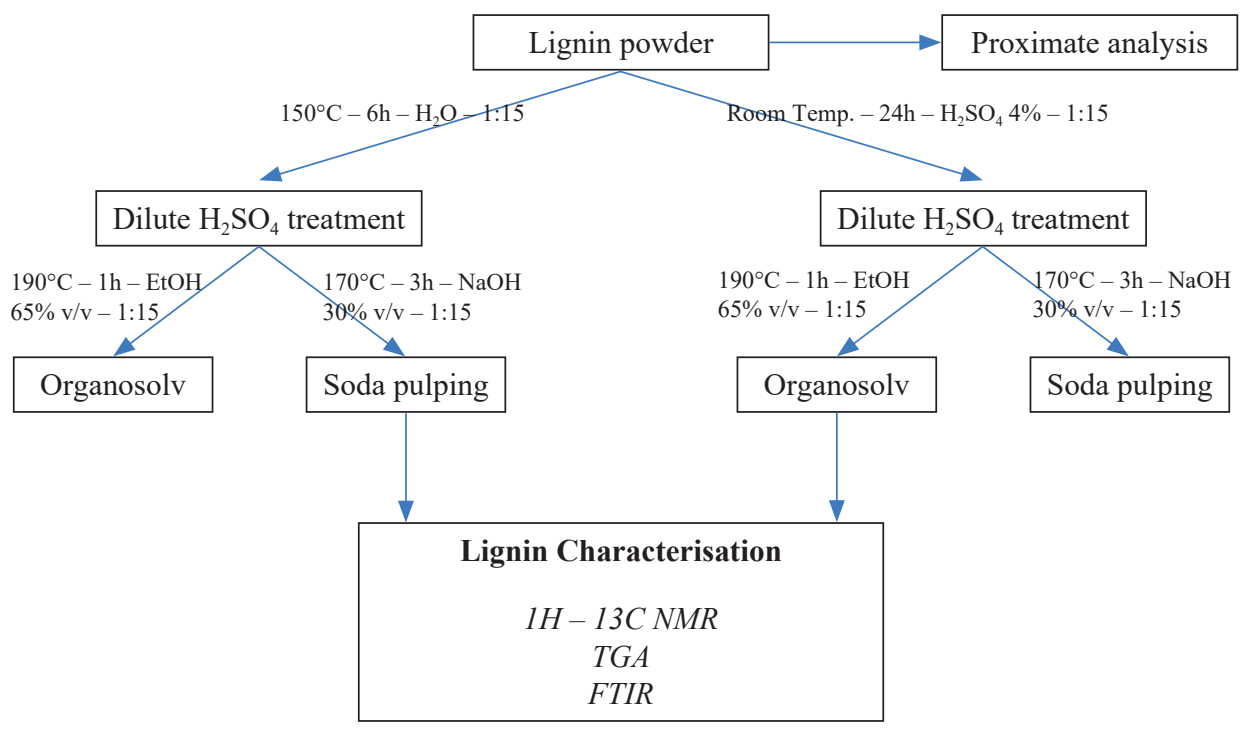

Figure 3: Overview of experimental procedure.

\subsection{Characterisation of Lignin}

\subsubsection{Severity factor}

Severity factor $\mathrm{R}_{0}$, obtained through the following formula leads to the severity of the process as shown below. ${ }^{7}$ It is used to describe the treatment conditions and it informs on the harshness of the process.

$$
\log \left(\mathrm{R}_{0}\right)=\log \left[\mathrm{t} \times\left(\mathrm{e}^{\frac{\mathrm{T}-\mathrm{T}_{\mathrm{Ref}}}{14.7}}\right)\right]
$$

In the quation, $\mathrm{t}$ is time $(\mathrm{min}), \mathrm{T}$ is temperature $\left({ }^{\circ} \mathrm{C}\right)$ and the reference temperature $\mathrm{T}_{\text {ref }}$ is $100^{\circ} \mathrm{C}$. The $\mathrm{pH}$ is obtained at the end of each experiment through the liquid obtained after filtration (liquor). Its measure is done through a pH-meter (SigmaAldrich pH 211). 


\subsubsection{FTIR spectroscopy}

The obtained lignin is analysed with an FTIR spectrophotometer in a direct transmittance mode using Perkin Elmer model System 2000 instrument at the region between $4000 \mathrm{~cm}^{-1}$ and $600 \mathrm{~cm}^{-1}$ with a resolution of $4 \mathrm{~cm}^{-1}$, and 100 scans are done.

\subsubsection{NMR spectroscopy}

Lignin will have to undergo an acetylation reaction before NMR analysis, in order to make it soluble in DMSO- $\delta_{6}$. The purpose is to transform -OH groups to acetyl groups. The procedure follows the method outlined by Sa'don et al. ${ }^{8}$

An amount of $500 \mathrm{mg}$ lignin is mixed with $7.5 \mathrm{ml}$ of a $1: 1$ pyridine/acetic anhydride mixture and stirred for $24 \mathrm{~h}$ at room temperature. Then, $75 \mathrm{ml} \mathrm{HCl}$ $1 \%(\mathrm{v} / \mathrm{v})$ are added dropwise to the mixture. A precipitate is formed, filtered and neutralised with an excess of distilled water. The precipitate is then dried in a $50^{\circ} \mathrm{C}$ oven for overnight and is eventually ready for NMR analysis.

The spectra are obtained with a Bruker Avance 500 NMR spectrometer in liquid state $\left(\mathrm{DMSO}-\delta_{6}\right.$ ) using a standard pulse program. Quantitative NMR spectra were attained using an inverse-gated decoupling (Waltz-16) pulse sequence to avoid Nuclear Overhauser Effect.

\section{RESULTS AND DISCUSSION}

\subsection{Proximate Analysis Results}

Proximate analysis results from this experiment are correlated with the previous studies as shown in Table 1. Since the biomass has a moisture content less than $30 \%$, it is suitable for thermochemical conversion. ${ }^{9}$ Proximate analysis thus confirms that coconut husks can be used in the pre-treatment processes. Besides, it confirms that coconut husk has a rather low ash content and a high lignin content for non-woody biomass.

Table 1: Proximate analysis of coconut husk.

\begin{tabular}{lccc}
\hline & This work & Aziz et al. $^{11}$ & Lertwattanaruk and Suntijitto $^{10}$ \\
\hline Moisture content (\%) & 11.67 & 13.3 & NA \\
Ash content (\%) & 2.5 & 2.1 & 2.65 \\
Extractives (\%) & 12.1 & 10.62 & NA \\
Klason lignin (\%) & 34.4 & 32.1 & 29.8 \\
\hline
\end{tabular}




\subsection{Lignin Recovery}

It has been found that post autohydrolysis lignin had a Klason lignin content of $45.5 \%$. This is an expected result. Autohydrolysis process breaks bonds in lignin structure, yielding more lignin fragments, hence increasing the percentage of lignin content.

After soda treatment, more pure lignin was eventually obtained. Lignin coming from autohydrolysis-soda was obtained with a yield of 9.05\%. Lignin from dilute acid-soda was obtained with a yield of $8.54 \%$. These yields are rather low compared to Aziz et al.results, that were closer to $30 \%$ yields. ${ }^{11}$ A higher severity for water treatment can explain why the Autohydrolysis process gave a slightly higher yield than the sulfuric acid process.

The small difference between the two yields indicates that both processes give almost the same amount of lignin, but it is not an indicator of lignin quality.

\subsection{Lignin Characterisation}

\subsubsection{Severity factor}

In Table 2, the $\mathrm{pH}$ decrease or increase for respectively dilute $\mathrm{H}_{2} \mathrm{SO}_{4}$ and soda treatments were expected, for their use directly an acid and a base. However, $\mathrm{pH}$ decreases also in organosolv and water treatment processes. It can be explained by the fact that $\mathrm{H}_{3} \mathrm{O}^{+}$ions are created in the medium through high temperature water autoionisation. These hydronium ions will act as acid catalysts that will hydrolyse hemicelluloses polysaccharides into monomers. From this reaction, acids will be produced (mainly acetic acid) and will be responsible for $\mathrm{pH}$ decrease. As for organosolv process, it also generates acetic acid through hemicellulose that helps acid hydrolysis and creation of phenolic hydroxyl groups, hence decreases the $\mathrm{pH} .{ }^{12}$

Table 2: Severity factor of different pre-treatment processes.

\begin{tabular}{lcccc}
\hline Process & $\mathrm{t}(\mathrm{min})$ & $\mathrm{T}\left({ }^{\circ} \mathrm{C}\right)$ & $\mathrm{pH}$ & $\log \left(\mathrm{R}_{0}\right)$ \\
\hline Autohydrolysis & 360 & 150 & 4.2 & 4.03 \\
Dilute $\mathrm{H}_{2} \mathrm{SO}_{4}$ & 2 & 170 & 1.6 & 2.36 \\
Organosolv & 60 & 190 & 4.3 & 4.43 \\
Soda pulping & 180 & 170 & 13.3 & 4.32 \\
\hline
\end{tabular}


About the different severity factors (in Table 2), the most severe process (autohydrolysis-soda) yielded a slightly higher yield. The same characteristic was observed in their organosolv treated biomass by Hussin et al. ${ }^{7}$

Besides, lignin treated with dilute acid underwent a less severe process than lignin treated with autohydrolysis, which could create differences between both lignin structures, as the reaction is different.

\subsubsection{FTIR analysis}

The obtained FTIR spectrum is displayed in Figure 4. This spectrum was interpreted on the IR tables and on the other hand thanks to previous studies relevant on oil palm fronds biomass treated with organosolv or soda process. ${ }^{8,13-15}$ The assignments for the IR bands are reported in Table 3.

IR Spectra of Lignin

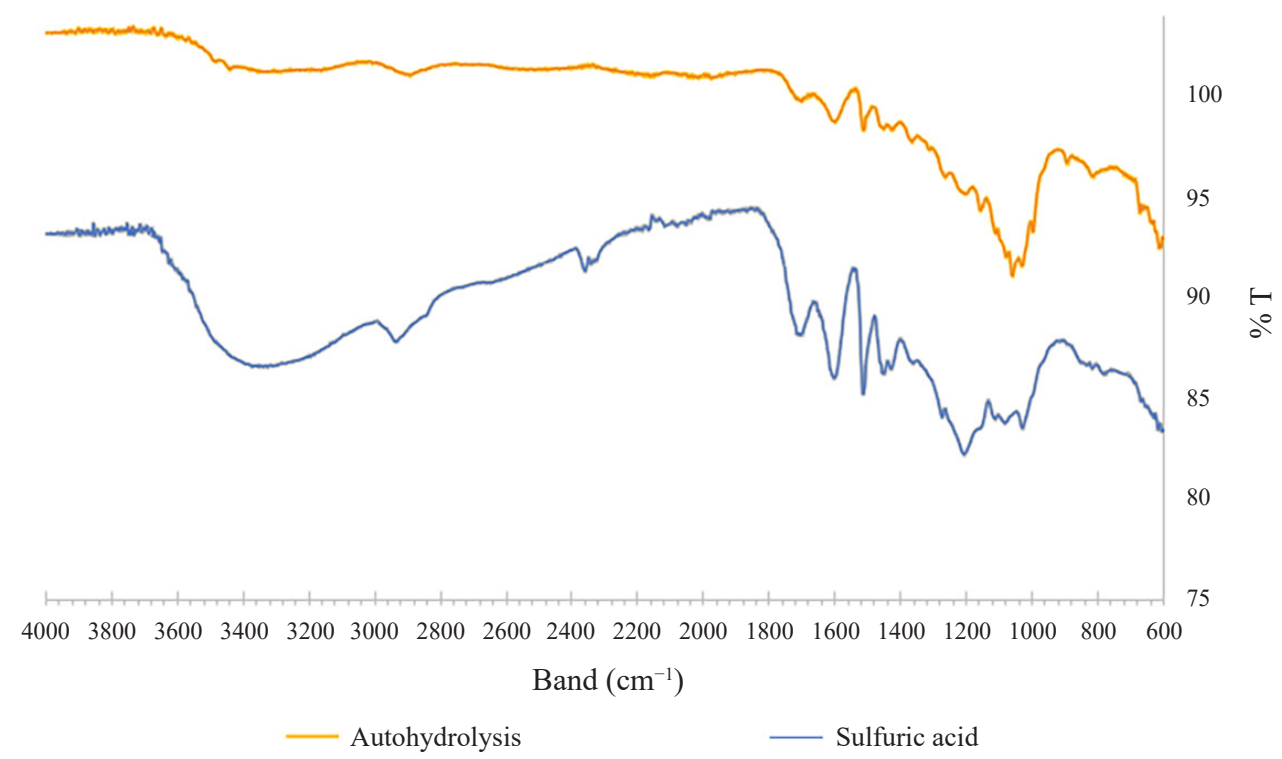

Figure 4: IR spectra of autohydrolysis and sulfuric acid treated lignins. 
Table 3: Assignment of IR bands of soda treated lignin.

\begin{tabular}{|c|c|c|}
\hline \multicolumn{2}{|c|}{ Band $\left(\mathrm{cm}^{-1}\right)$} & \multirow{2}{*}{ Assignment } \\
\hline Autohydrolysis & Dilute acid & \\
\hline 3326 & 3330 & O-H stretching \\
\hline 2892 & 2936 & Aliphatic $\left(\mathrm{CH}_{2}\right.$ and $\mathrm{CH}$ stretching $)$ \\
\hline 1700 & 1705 & $\mathrm{C}=\mathrm{O}$ stretching \\
\hline 1600 & 1602 & $\mathrm{C}=\mathrm{C}$ stretching from aromatic ring \\
\hline 1365 & 1362 & $\mathrm{O}-\mathrm{H}$ bending in phenolic groups \\
\hline 1312 & - & C-O stretching (syringyl unit) \\
\hline 1201 & 1206 & $\mathrm{C}-\mathrm{O}-\mathrm{H}$ in guaiacyl and syringyl units \\
\hline 1157 & 1161 & Typical H-G-S absorption \\
\hline 1111 & 1112 & Ar-C-H deformation in syringyl unit \\
\hline 1030 & 1029 & $\mathrm{C}-\mathrm{O}-\mathrm{C}$ in guaiacyl unit \\
\hline 813 & 816 & $\mathrm{C}-\mathrm{H}$ (syringyl unit) \\
\hline
\end{tabular}

In the band assignments, $3330 \mathrm{~cm}^{-1}$ is the typical intense and broad band due to -OH stretching group. Other alcohol bands, $1200 \mathrm{~cm}^{-1}$ and $1360 \mathrm{~cm}^{-1}$ are typical phenolic groups (as expected $1200 \mathrm{~cm}^{-1}$ and $1310-1410 \mathrm{~cm}^{-1}$ ). It can be seen that $3330 \mathrm{~cm}^{-1}$ and $1200 \mathrm{~cm}^{-1}$ peaks are more intense for $\mathrm{H}_{2} \mathrm{SO}_{4}$ treatment, which can mean a more severe process generates less alcohol groups. It could be showed a greater presence of xylose (a sugar containing $4-\mathrm{OH}$ groups) is verified when the severity factor is lower. ${ }^{16}$

The peak at $1030 \mathrm{~cm}^{-1}\left(1000-1050 \mathrm{~cm}^{-1}\right)$ and aliphatic peaks at around $2900 \mathrm{~cm}^{-1}$ and $815 \mathrm{~cm}^{-1}$ were expected since lignin structure does contain methoxy groups and carbon chains.

Aromatic rings presence is confirmed with $1600 \mathrm{~cm}^{-1}$ and $1111 \mathrm{~cm}^{-1}$ bands, while carbonyl group is verified at $1705 \mathrm{~cm}^{-1}$ (as expected between $1705 \mathrm{~cm}^{-1}$ and $\left.1725 \mathrm{~cm}^{-1}\right)$.

At $1155 \mathrm{~cm}^{-1}$ and $1312 \mathrm{~cm}^{-1}$ bands are also typical bands present in lignin that confirm the presence of purified lignin in the sample. From the previous papers, it revealed that $\mathrm{S}$ units $\left(1312 \mathrm{~cm}^{-1}, 1102 \mathrm{~cm}^{-1}, 813 \mathrm{~cm}^{-1}\right)$ and $\mathrm{G}$ units $\left(1200 \mathrm{~cm}^{-1}\right.$, $1028 \mathrm{~cm}^{-1}$ ) are present in the lignin structure.

\subsubsection{NMR analysis}

Main peaks in ${ }^{13} \mathrm{C}$ spectrum are identified and illustrated in Figure 5. In addition, an aromatic equivalence has been calculated as summarised in Table 4. Indeed, previous studies have shown the region between $102 \mathrm{ppm}$ and $162 \mathrm{ppm}$ corresponds 
to an aromatic ring. This aromatic ring is made of 6 aromatic carbons bound to 0.12 vinylic carbons (from the unsaturated side chain of coniferic and coumaric moieties). ${ }^{15,16}$ This aromatic ring can be set as the reference and is the equivalent of 6.12 carbons.

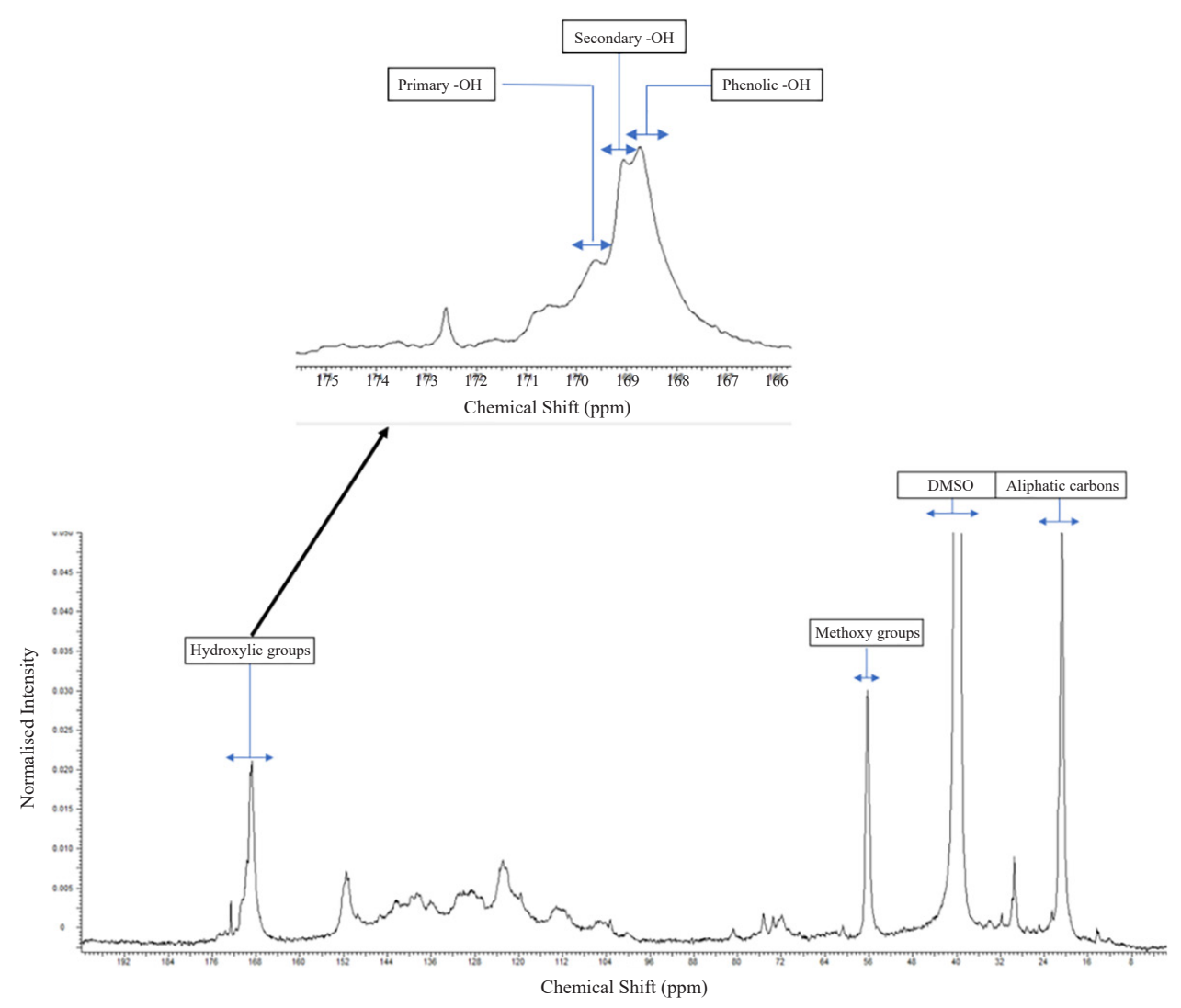

Figure 5: Assignment of ${ }^{13} \mathrm{C}$ NMR spectrum of autohydrolysis + soda treated lignin.

Therefore, the integration value between $102 \mathrm{ppm}$ and $162 \mathrm{ppm}$, divided by 6.12 is the integration value of one aromatic benzene ring. In our case, the integration value is 234 . Thus, 38.2 as integration value corresponds to one Ar. The greater the value, the greater the presence of the group in the lignin structure.

Table 4 shows that phenolic groups are more common than aliphatic alcohols in soda lignin. This is in accordance in previous study showed than soda and Kraft lignins are rich in phenolic groups compared to organosolv lignin which is rather poor in phenolic groups as described by Hussin et al. ${ }^{14}$ This is probably due to soda lignin that favours aryl-ether cleavage during the reaction. 
Table 4: Assignment of ${ }^{13} \mathrm{C}$ NMR Spectroscopy.

\begin{tabular}{lccc}
\hline Group & Range $(\mathrm{ppm})$ & Integral $(\mathrm{mm})$ & Value/Ar \\
\hline Primary -OH & $171-172$ & 5 & 0.13 \\
Secondary -OH & $169-170$ & 11 & 0.28 \\
Phenolic -OH & $166-169$ & 18 & 0.47 \\
Methoxy -O-Me & $56-59$ & 43 & 1.12 \\
DMSO & 40 & $/$ & $/$ \\
Aliphatic carbon & $18-22$ & $/$ & $/$ \\
\hline
\end{tabular}

\section{CONCLUSION}

It is concluded that lignin can be isolated from coconut husks. Two-step pretreatment (autohydrolysis-Soda treatments and dilute $\mathrm{H}_{2} \mathrm{SO}_{4}$-Soda treatments) yielded a rather pure lignin, whose structure contains guaiacyl and syringyl units, and a great quantity of phenolic groups. The general output of lignin recovery is less than $10 \%$, which is a problem if delignification of coconut husks had to be processed on an industrial scale. Considering previous studies, it would be interesting to adjust experimental conditions or changes of parameters in order to increase yield of lignin. Autohydrolysis and organosolv lignin are two environmental-friendly processes, the combination of those two for efficient lignin recovery is of interest.

\section{ACKNOWLEDGEMENTS}

Authors are pleased to acknowledge Universiti Sains Malaysia (USM) for providing financial assistance on account of the USM Research University Incentive Grant (1001/PKIMIA/8011077). Nur Hanis Abd. Latif acknowledges USM for the USM Fellowship scheme. Bryan Carre was the attachment student from Universite de Lorraine, France.

\section{REFERENCES}

1. Alonso, D. M., Wettstein, S. G. \& Dumesic, J. A. (2012). Bimetallic catalysts for upgrading of biomass to fuels and chemicals. Chem. Soc. Rev., 41(24), 1-24, https://doi.org/10.1039/c2cs35188a

2. Zhu, J. \& Pan, X. (2010). Woody biomass pretreatment for cellulosic ethanol production: Technology and energy consumption evaluation. Biores. Technol., 101(13), 4992-5002, https://doi.org/10.1016/j.biortech.2009.11.007.

3. Karp, S. G. et al. (2013). Pretreatment strategies for delignification of sugarcane bagasse: A review. Braz. Arch. Biol. Technol., 56(4), 679-689. 
4. Gosselink, R. et al. (2004). Co-ordination network for lignin-standardization, production and application adapted to market requirements (EUROLIGNIN). Ind. Crop Prod., 20(2), 121-129, https://doi.org/10.1016/j.indcrop.2004.04.015.

5. Herruzo, F. G., Jimenez, F. M. \& Jimenez, J. J. R. (1984). Possibilities of using lignin in the chemical industry. Chem. Eng., 187, 249-254.

6. Zoumpoulakis, L. \& Simitzis, J. (2001). Ion exchange resins from phenol/ formaldehyde resin-modified lignin. Polym. Int., 50(3), 277-283, https://doi. org/10.1002/pi.621.

7. Hussin, M. H. et al. (2014). Investigation on the structure and antioxidant properties of modified lignin obtained by different combinative processes of oil palm fronds (OPF) biomass. Ind. Crop. Prod. 52, 544-551, https://doi.org/10.1016/j. indcrop.2013.11.026

8. Sa'don, N. A., Rahim, A. A. \& Hussin, M. H. (2017). The effect of p-nitrophenol toward the structural characteristics and antioxidant activity of oil palm fronds (OPF) lignin polymers. Int. J. Biol. Macromol., 98, 701-708, https://doi. org/10.1016/j.ijbiomac.2017.01.137.

9. McKendry, P. (2002). Energy production from biomass. Part 2: Conversion technologies. Biores. Technol., 83(1), 47-54.

10. Lertwattanaruk, P. \& Suntijitto, A. (2015). Properties of natural fibre cement materials containing coconut coir and oil palm fibers for residential building applications. Contr. Build. Mater., 94, 664-669, https://doi.org/10.1016/j. conbuildmat.2015.07.154.

11. Aziz, N. A. et al. (2019). Reinforced lignin-phenol-glyoxal (LPG) wood adhesives from coconut husk. Int. J. Biol. Macromol., 141, 185-196, https://doi.org/10.1016/j. ijbiomac.2019.08.255.

12. Tejado, A. et al. (2007). Physico-chemical characterization of lignins from different sources for use in phenol-formaldehyde resins synthesis. Biores. Technol., 98(8), 1655-1663, https://doi:10.1016/j.biortech.2006.05.042.

13. Laboratoire de Méthodologies et Synthèse de Produits Naturels. (2019). Table des Frequences de Vibration Carateristics en IR. Retrieved 18 June 2019 from http://lmspn.uqam.ca/fichiers/tablesir.pdf.

14. Hussin, M. H. et al. (2013). Physicochemical characterization of alkaline and ethanol organosolv lignins from oil palm (Elaeis guineensis) fronds as phenol substitutes for green material applications. Ind. Crop. Prod., 49, 23-32, https://doi.org/10.1016/j.indcrop.2013.04.030.

15. Capanema, E. A., Balakshin, M. Y. \& Kadla, J. F. (2004). A comprehensive approach for quantitative lignin characterization by NMR spectroscopy. J. Agric. Food Chem., 52(7), 1850-1860.

16. El Hage, R. et al. (2009). Characterization of milled wood lignin and ethanol organosolv lignin from miscanthus. Polym. Degrad. Stab., 94, 1632-1638, https://doi.org/10.1016/j.polymdegradstab.2009.07.007 